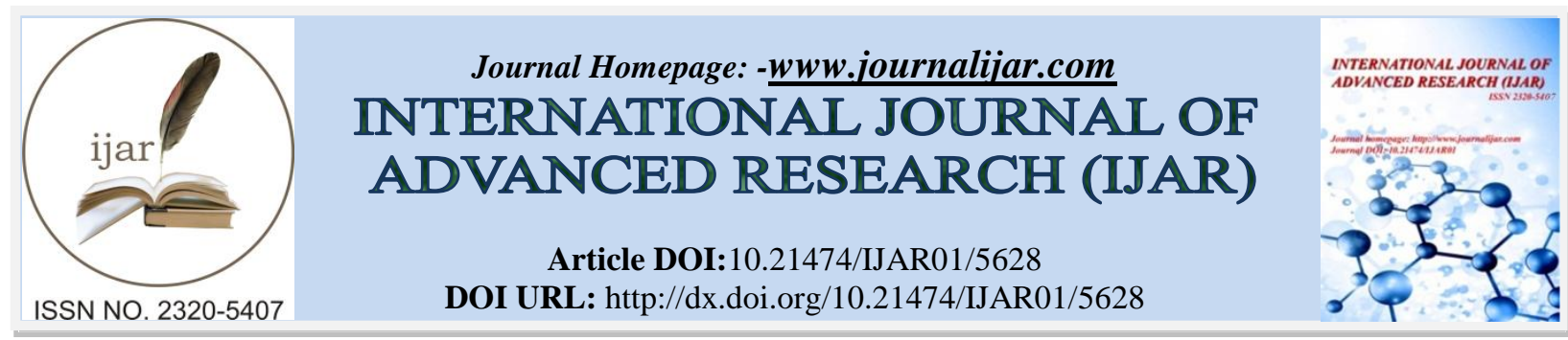

RESEARCH ARTICLE

\title{
THE NEW BENEFICIAL APPLICATION OF CAFFEINE AS A PROMOTING FACTOR OF SPERM MOTILITY COMBINED WITH DENSITY GRADIENT CENTRIFUGATION TECHNIQUE FOR BEST YIELD FOR ASTHENOZOOSPERMIC AND OLIGOZOOSPERMIC MEN.
}

\author{
Naam A. Hamza, Mohammad O. Selman and Hayder A. L. Mossa. \\ High Institute of Infertility Diagnosis and Assisted Reproductive Technologies, Al- Nahrain University, Baghdad- \\ IRAQ.
}

\section{Manuscript Info}

Manuscript History

Received: 15 August 2017

Final Accepted: 17 September 2017

Published: October 2017

Key words:-

Asthenozoospermia,Oligozoospermia,

Density Gradient Centrifugation

,Caffeine.

\section{Abstract}

Background: Seminal fluid of males is varied in quality, not only between males but also within a single sample. A verity of in vitro sperm preparation techniques were developed to separate normal and motile spermatozoa from other constituents of sample to provide successful assisted reproductive techniques.

Objectives:The goal of this study was to compare the effects of the four in vitro sperm activation techniques on sperm function parameters specially sperm motility ofasthenozoospermicand oligozoospermicsemen samples.

Subjects, Materials and Methods:Thirty-five asthenozoospermic and fifteen oligozoospermic men were participated in this study during their attendance to the Infertility Clinic at High Institute for Infertility Diagnosis and Assisted Reproductive Technologies; Al- Nahrain University. Collection of semen samples and seminal fluid analysis was done according to WHO (1999) and WHO (2010). Each semen sample was divided into four parts. The first one prepared as in vitro sperm activation using the direct swim-up technique, the second using indirect swim-up technique,the third using density gradient centrifugation technique, while the last part prepared using density gradient centrifugation and Caffeine(combined techniques).

Results: A significant increase was observed in the sperm function parameters including sperm motility and morphologically normal sperm for asthenozoospermic and oligozoospermic samples when using density gradient centrifugation and Caffeine as compared to density gradient centrifugation alone.Also, there was a significant increase was observed in the same sperm function parameters when using density gradient centrifugation as compared to direct swim-up technique and indirect swim-up technique.

Conclusion: In this study, the outcome of sperm function parameters using combined density gradient technique with Caffeine were higher than other techniques, especially when using a low quality of semen samples such as decreased sperm motility, therefore it was fit in cases ofasthenozoospermia and oligozoospermia which are taken as examples of infertile group in this study.

Copy Right, IJAR, 2017,. All rights reserved. 


\section{Introduction:-}

Assisted reproductive technologies (ART's) were advanced through the earlier decades to produce high-yielding numbers of embryos, and have been revealed the need for suitable and effective techniques of sperm treatment in the laboratory $^{(1)}$.Many of sperm separation or isolation methods exist to select spermatozoa. These methods include swim-up methods, density gradient centrifugation, Pentoxifylline wash, and others. A number of techniques have been developed to separate viable sperm from the seminal fluid for use in ART's ${ }^{(2)}$.

The density gradient centrifugation technique can be modified to treat the issues of each individual specimen, and it is the method of choice for preparation of the sperm in the majority of ART's and andrologylaboratories ${ }^{(3)}$.

Spermatozoa of mammalians do not have the ability for fertilize the ova immediately after ejaculation process; however, the sperm are gain this ability after capacitation and hyperactivation process ${ }^{(4,5)}$. One of the continuous physiological processes occurring for spermatozoa to obtain the fertilizing efficiency is hyperactivity. Motility of sperm is very important to penetrate the cumulus cells and zonapellucida surrounding the oocyte ${ }^{(6,7)}$.Moreover, a change in the sperm motility can be indicated by hyperactivation, the change of motility pattern is from steady and symmetrical flagellate bends to high amplitude and asymmetrical flagellate bends ${ }^{(8,9)}$.

In ART's and andrology laboratories, to study the hyperactivation of sperm there are many ingredients were used as an attempt to improve the semen quality by using Caffeine as an example of sperm motility stimulating factors ${ }^{(10)}$.

Caffeine is a cyclic nucleotide phosphodiesterase inhibitor, causing in an increase in the intracellular cyclic adenosinemonophosphate (cAMP), stimulating of capacitation and the spermacrosomal reaction ${ }^{(11)}$, and increasing of sperm motility ${ }^{(12)}$.Depending on the concentration of calcium ions, Caffeine may have a direct effect on metabolism of cells ${ }^{(13)}$.

\section{Subjects, Materials and Methods:-}

The study was done for thirty- five asthenozoospermic and fifteen oligozoospermic infertile men of different age, during their attendance to the High Institute of Infertility Diagnosis and Assisted Reproductive Technologies (ART's) at Al- NahrainUniversity. The samples of semen were collected and analysis was done according to WHO (1999, 2010). Every sample was divided into four parts. The first one using the density gradient centrifugation technique, the second one using the density gradient centrifugation technique with Caffeine, the third one using the centrifugation swim-up migration technique and the last one using direct swim-up technique, then sperm parameters were assessed for these four techniques and the results were statistically analyzed.

\section{Discontinuous Density Gradients Technique with Caffeine:-}

This sperm preparation method was prepared as same as discontinuous density gradients technique with adding $0.5 \mathrm{~mL}$ of Caffeine stock in the tube to the pellet when the supernatant was discarded and sperm parameters were examined by aspiration of $10 \mu \mathrm{L}$ with micropipette which put on a slid and covered with cover slip.

Statistical Analysis:-The Statistical Analysis System- SAS (2016) program was used to effect of difference factors in study parameters.Least significant difference -LSD test was used to significant compare between means in this study $^{(14)}$.

\section{Results:-}

After in vitro sperm activation for asthenozoospermic and oligozoospermic samples using these four techniques, a significant increase was observed in the sperm function parameters including sperm motility and morphologically normal sperm as compared to pre-activation. Besides, it was observed a significant or reduction in the other sperm function parameters (concentration, agglutination and round cells count). Furthermore, the present study showed a significant increase in certain sperm function parameters such as sperm motility stimulation, progressive sperm motility, and morphologically normal sperm for all types of samples using combined techniques (density gradient centrifugation and Caffeine) as compared to the three other techniques(table 1,2). In all types of samples, it was appeared that density gradient centrifugation combined with Caffeine resulted in significantly superior results and shown a positive effect for the 
concentration and total number of progressive motile of the sperm rather than direct swim- up technique, indirect swim- up technique, and density gradient centrifugation technique(table 1,2).

Table 1:- Sperm parameters for asthenozoospermic male group pre-and post in vitro sperm activation.

\begin{tabular}{|c|c|c|c|c|c|c|}
\hline \multirow{3}{*}{$\begin{array}{l}\text { Certain Sperm } \\
\text { Function } \\
\text { Parameters }\end{array}$} & \multicolumn{6}{|c|}{$\mathbf{M} \pm \mathbf{S E}$} \\
\hline & \multirow{2}{*}{$\begin{array}{l}\text { Sperm } \\
\text { Concentration } \\
\text { Value }(\mathbf{m} / \mathbf{m l})\end{array}$} & \multicolumn{2}{|c|}{$\begin{array}{l}\text { Progressive Sperm } \\
\text { Motility }(\%)\end{array}$} & \multirow{2}{*}{$\begin{array}{l}\text { Non- } \\
\text { Progressive } \\
\text { Sperm } \\
\text { Motility (\%) } \\
\text { Grade C } \\
\end{array}$} & \multirow{2}{*}{$\begin{array}{l}\text { Immotile } \\
\text { Sperm } \\
(\%) \\
\text { Grade D }\end{array}$} & \multirow{2}{*}{$\begin{array}{l}\text { Morphologically } \\
\text { Normal Sperm } \\
\qquad(\%)\end{array}$} \\
\hline & & Grade A & Grade B & & & \\
\hline Before activation & $49.23 \pm 3.54 \mathrm{a}$ & $\begin{array}{l}0.742 \\
\pm 0.37 \mathrm{~d} \\
\end{array}$ & $\begin{array}{c}28.23 \pm \\
1.63 \mathrm{~d} \\
\end{array}$ & $37.46 \pm 1.34 \mathrm{a}$ & $\begin{array}{c}34.08 \pm \\
1.75 \mathrm{a} \\
\end{array}$ & $34.00 \pm 1.77 \mathrm{~d}$ \\
\hline \multicolumn{7}{|c|}{ After in vitro activation } \\
\hline Direct technique & $19.23 \pm 2.15 \mathrm{~d}$ & $\begin{array}{l}1.94 \pm \\
0.62 \mathrm{~d} \\
\end{array}$ & $\begin{array}{c}40.48 \pm \\
1.82 \mathrm{c} \\
\end{array}$ & $39.23 \pm 1.56 \mathrm{a}$ & $\begin{array}{c}18.29 \pm \\
1.13 \mathrm{~b}\end{array}$ & $49.11 \pm 1.57 \mathrm{c}$ \\
\hline $\begin{array}{c}\text { Indirect } \\
\text { technique }\end{array}$ & $25.28 \pm 2.43 \mathrm{c}$ & $\begin{array}{l}4.08 \pm \\
0.97 \mathrm{c}\end{array}$ & $\begin{array}{l}47.37 \pm \\
2.08 \mathrm{~b}\end{array}$ & $36.40 \pm 2.54 \mathrm{a}$ & $\begin{array}{l}12.14 \pm \\
1.16 \mathrm{c}\end{array}$ & $57.20 \pm 1.75 b c$ \\
\hline Density gradient & $30.70 \pm 2.73 b c$ & $\begin{array}{l}7.45 \pm \\
1.44 \mathrm{~b}\end{array}$ & $\begin{array}{c}53.48 \pm \\
1.60 \mathrm{~b} \\
\end{array}$ & $30.94 \pm 2.26 \mathrm{~b}$ & $\begin{array}{l}8.11 \pm \\
1.21 \mathrm{~cd}\end{array}$ & $65.97 \pm 1.63 \mathrm{ab}$ \\
\hline $\begin{array}{l}\text { Density gradient } \\
\text { + Caffeine }\end{array}$ & $36.80 \pm 2.73 b$ & $\begin{array}{c}11.88 \pm \\
1.92 \mathrm{a}\end{array}$ & $\begin{array}{c}59.80 \pm \\
1.48 \mathrm{a}\end{array}$ & $24.08 \pm 2.15 \mathrm{c}$ & $\begin{array}{l}4.23 \pm \\
0.75 \mathrm{~d}\end{array}$ & $75.00 \pm 1.57 \mathrm{a}$ \\
\hline LSD value & $7.215 *$ & $2.679 *$ & $6.463 *$ & $5.225 *$ & $5.507 *$ & $11.726 *$ \\
\hline \multicolumn{7}{|c|}{$\begin{array}{l}*(\mathrm{P}<0.05) \\
\text { Means having with the different letters in same column differed significantly. } \\
\mathrm{M} \pm \mathrm{SE} \text { : Mean } \pm \text { Standard error, } \mathrm{N}=35\end{array}$} \\
\hline
\end{tabular}

Table 2:- Sperm parameters for oligozoospermic male group pre-and post in vitrosperm activation.

\begin{tabular}{|c|c|c|c|c|c|c|}
\hline \multirow{3}{*}{$\begin{array}{c}\text { CertainSperm } \\
\text { Function Parameters }\end{array}$} & \multicolumn{6}{|c|}{ Mean \pm SE } \\
\hline & \multirow[t]{2}{*}{$\begin{array}{l}\text { Sperm } \\
\text { Concentration } \\
\text { value }(\mathrm{m} / \mathbf{m l})\end{array}$} & \multicolumn{2}{|c|}{$\begin{array}{l}\text { Progressive sperm } \\
\text { motility }(\%)\end{array}$} & \multirow{2}{*}{$\begin{array}{l}\text { Non- } \\
\text { progressive } \\
\text { sperm } \\
\text { motility }(\%) \\
\text { Grade C }\end{array}$} & \multirow{2}{*}{$\begin{array}{l}\text { Immotile } \\
\text { sperm } \\
(\%) \\
\text { Grade D }\end{array}$} & \multirow[t]{2}{*}{$\begin{array}{l}\text { Morphologically } \\
\text { Normal sperm } \\
(\%)\end{array}$} \\
\hline & & Grade A & $\begin{array}{c}\text { Grade } \\
\text { B }\end{array}$ & & & \\
\hline Before activation & $11.13 \pm 0.96 \mathrm{a}$ & $\begin{array}{l}0.60 \pm \\
0.10 \mathrm{c} \\
\end{array}$ & $\begin{array}{c}25.06 \pm \\
2.86 \mathrm{~d} \\
\end{array}$ & $\begin{array}{c}33.26 \pm 2.10 \\
b\end{array}$ & $\begin{array}{l}14.90 \pm \\
3.85 \mathrm{~cd} \\
\end{array}$ & $15.11 \pm 3.90 \mathrm{~d}$ \\
\hline \multicolumn{7}{|c|}{ After in vitro activation } \\
\hline Direct technique & $3.38 \pm 0.49 \mathrm{c}$ & $\begin{array}{c}0.876 \pm \\
0.54 \mathrm{c} \\
\end{array}$ & $\begin{array}{c}34.13 \pm \\
3.12 \mathrm{c}\end{array}$ & $\begin{array}{c}39.20 \pm 2.84 \\
\mathrm{a} \\
\end{array}$ & $\begin{array}{c}25.86 \pm \\
2.85 \mathrm{a} \\
\end{array}$ & $42.67 \pm 1.99 \mathrm{c}$ \\
\hline Indirect technique & $4.15 \pm 0.66 b c$ & $\begin{array}{l}2.07 \pm \\
1.08 \mathrm{bc}\end{array}$ & $\begin{array}{l}39.00 \pm \\
3.52 \mathrm{bc}\end{array}$ & $\begin{array}{c}36.80 \pm 2.89 \\
\mathrm{ab}\end{array}$ & $\begin{array}{l}21.46 \pm \\
2.90 \mathrm{~b}\end{array}$ & $49.00 \pm 2.59 b c$ \\
\hline Density gradient & $5.58 \pm 0.78 b c$ & $\begin{array}{l}3.60 \pm \\
1.47 \mathrm{~b} \\
\end{array}$ & $\begin{array}{l}43.00 \pm \\
3.21 \mathrm{~b} \\
\end{array}$ & $\begin{array}{c}35.53 \pm 3.10 \\
\mathrm{ab}\end{array}$ & $\begin{array}{l}17.86 \pm \\
4.29 \mathrm{bc}\end{array}$ & $56.46 \pm 3.12 \mathrm{ab}$ \\
\hline $\begin{array}{c}\text { Density gradient + } \\
\text { Caffeine }\end{array}$ & $7.04 \pm 0.87 b$ & $\begin{array}{l}6.33 \pm \\
2.12 \mathrm{a}\end{array}$ & $\begin{array}{l}50.46 \pm \\
2.93 \mathrm{a}\end{array}$ & $\begin{array}{c}33.26 \pm 2.97 \\
b\end{array}$ & $\begin{array}{c}10.93 \pm \\
3.42 \mathrm{~d} \\
\end{array}$ & $65.93 \pm 3.39 a$ \\
\hline LSD value & $3.530 *$ & $2.094 *$ & $6.283 *$ & $5.471 *$ & $4.392 *$ & $10.613 *$ \\
\hline \multicolumn{7}{|c|}{$\begin{array}{l}*(\mathrm{P}<0.05) \\
\text { Means having with the different letters in same column differed significantly. } \\
\mathrm{M} \pm \mathrm{SE}: \text { Mean } \pm \text { Standard error, } \mathrm{N}=15\end{array}$} \\
\hline
\end{tabular}

\section{Discussion:-}

The importance of sperm preparation techniques in ART's, is to obtain the highest sperm recovery and in vitro treatment of spermatozoa to improve their function like, motility and improve or maintain the functional capacity for successful fertilization through supplementation of protective media ${ }^{(15)}$. 
The results of sperm concentrations parameter forasthenozoospermic and oligozoospermic semen samples showed a significant $(\mathrm{P}<0.05)$ decrease in the concentration of sperm in post- in vitro sperm activation techniques; direct swimup,in direct swim -up, density gradient and density gradient combined with Caffeine as compared with preactivation sperm concentration. This reduction occurs as a result of abnormal and dead sperms exclusion during sperm preparation techniques.

Density gradient centrifugation technique with and without Caffeine sperm migrate through density of media and then from pellet to upper media, the data of this study showed the high concentration rate of sperm was in these two techniques. These results were in contract with other studies that activate and isolate spermatozoa in vitro sperm preparation using density gradient centrifugation techniques compared with other techniques, as reported by Sakkas, et $a l^{(16)}$.

In this study there isasignificant $(\mathrm{P}<0.05)$ result for the four techniques of increase sperm motility noticed with progressive motile sperm (grade A and grade B) as grade system which used. This result due to activation of sperm with culture media, so sperm of grade B become grade A and the same for other grades. But, the data of this study showed the high percentage of motility was found with density gradient combined with Caffeine. Since cyclic AMP is known to rise the sperm motility, high concentrations of Caffeine can cause an inhibition of cyclic adenosine 3',5'monophosphate (AMP) phosphodiesterase when added to semen thus in turn increase sperm motility, while Caffeine in low concentrations produced a dose-dependent increase in motility of sperm, which suggest that Caffeine can stimulate motility of sperm by a mechanism other than inhibition of phosphodiesterase ${ }^{(17)}$.

These results were similar to other studiesthat reported a significant stimulatory result of Caffeine on motility of sperm was observed, when compared with other chemicals used to stimulate motility and improve the effect of Caffeine activated the non-motile live $\operatorname{spermatozoa}^{(17,18,19,20)}$.

In general, density gradient centrifugation technique showed result high than other techniques as a result of silane coated silica that used for sperm preparation, and these result agreements with the findings of other studies that reported by the main improving role of this technique on the recovery of motile spermatozoa ${ }^{(21,22,23,24)}$.

The high result showed with density gradient centrifugation technique with and without Caffeine, the reason of these result of this techniqueis directly linked to the gradient material which used to prepare sperm cells separation in the presence of round cells in large number, antisperm antibodies and low recovery motile spermatozoa in samples (25) ; on other hand, the separation of sperm based on their motility and morphology with used of activated medium which a cause of normal morphologically and motile sperm separation from the total sperm population ${ }^{(26)}$.

In this study, the best choice to prepare or select functional sperm depending on the feature of the semen samples for asthenozoospermic, oligozoospermic samples is density gradient centrifugation technique specially when combined with Caffeine, in which yielded high result for sperm motility and morphology more than other techniques which used in this study. ${ }^{(27,28,29)}$.

The Active progressive sperm motility grades A and B are increased following activation for 30 minutes and one hour compared with before activation ${ }^{(30)}$, because activation techniquesofspermlead to excellent yields in motile spermatozoa especially in density gradient technique combined with Caffeine ${ }^{(31)}$, in addition to that the components of liquid artificial medium may improve the percentage of morphologically normal sperm and progressive motility because it diluted and reduced the semen viscosity ${ }^{(20)}$.Therefore, these good sperm preparation techniques can improve sperm quality by selecting high percentage of motile and morphologically normal spermatozoa ${ }^{(32)}$.

\section{References:-}

1. Camargo L, VianaJ.H,Sa W.F, Ferreira A, Ramos A, and FilhoV. Factors influencing in vitroembryoproduction.Animal Production.2006; 3: 19-28.

2. Spalekova E, Makarevich A, and Pivko J.Effect of Caffeine on parameter of ram sperm motility. Slovak J. Anim. Sci. 2011; 44(2):78-83.

3. Yanagimachi R. Mammalian fertilization: In The Physiology of Reproduction,Knobil E, and Neill J, Eds. Raven Press, New York, NY, USA.1994; 189-317.

4. Suarez S, and Ho H. Hyperactivated motility in sperm. Reproduction in Domestic Animals.2003; 38(2):119-124. 
5. Stauss C, VottaT, and Suarez S. Sperm motility hyperactivation facilitates penetration of the hamster zonapellucida.Biology of Reproduction. 1995; 53(6):1280-1285.

6. Ho H, GranishK, and Suarez S. Hyperactivated motility of bull sperm is triggered at the axonemeby $\mathrm{Ca}^{2+}$ and not Camp. Developmental Biology. 2002; 250(1):208-217.

7. Suarez S and Ho H. Control of hyperactivation in sperm.Human Reproduction Update.2008; 14(6): 647-657.

8. Saeki K, Nagao Y, Hoshi M, and Nagai M. Effect of heparin, sperm concentration and bull variation on in vitro fertilization of bovine oocytes in a protein- free medium. Theriogenology.1995; 43(4):751-759.

9. Kreysing U, Nagai T, and Niemann H. Male - dependent variability of fertilization and embryo development in two bovineinvitrofertilization systems and the effect of casein phosphopeptides (CPPs).Reproduction, Fertility and Development. 1997; 9(4):465-474.

10. Numabe T, Oikawa T,Kikuchi T, and HoriuchiT. Pentoxifylline improves in vitro fertilization and subsequent development of bovine oocytes. Theriogenology.2001; 56(2):225-233.

11. Tartaglione $\mathrm{C}$ and Ritta $\mathrm{M}$. Prognostic value of spermatological parameters as predictors of in vitro fertility of frozen-thawed bull semen. Theriogenology. 2004; 62(7):1245-1252.

12. FunahashiH, and Nagai T. Regulation of in vitro penetration of frozen-thawed boar spermatozoa by Caffeine and Adenosine. Molecular Reproduction and Development.2001; 58(4):424-431.

13. Park C, Ohgoda O, and Niwa K. Penetration of bovine follicular oocytes by frozen-thawed spermatozoa in the presence of Caffeine and heparin.Journal of Reproduction and Fertility.1989; 86(2):577-582.

14. SAS. 2016. Statistical Analysis System, User's Guide. Statistical. Version $9.1^{\text {th }}$ ed. SAS. Inst. Inc. Cary. N.C. USA

15. Astarto N W, Tjahyadi D, and JatnikasariS.Comparison between two-layer density gradient and three-layer density gradient technique for sperm preparation at aster fertility clinic, Dr.HasanSadikin General Hospital.IJIHS.2014;2(1):40-4.

16. Sakkas D , Manicardi G, Tomlinson M, Mandrioli M, Bizzaro D, Bianchi P G, andBianchi U. The use of two density gradient centrifugation techniques and the swim-up method to separate spermatozoa with chromatin and nuclear DNA anomalies. Human Reproduction. 2000;15( 5): 1112-1116.

17. Levin RM, Greenberg SH, and Wein AJ. Quantitative analysis of the effects of Caffeine on sperm motility and cyclic adenosine 3',5'-monophosphate (AMP) phosphodiesterase. FertilSteril. 1981;36(6):798-802.

18. Makler A, Makler E, Itzkovitz J, and Brandes JM. Factors affecting sperm motility. IV. Incubation of human semen with Caffeine, Kallikrein, and other metabolically active compounds. FertilSteril. 1980;33(6):624-30.

19. Tashiro H, Watanabe K, Takizawa H, Shibazaki Y, and Yoshida H. The effect of kallikrein and Caffeine on the sperm survival of cryopreserved semen in patients with oligozoospermia. NCBI. 1992.

20. Ibrahim A, Barakat MA, Galewan D F, and Dkhil M A.Effect of various concentrations of Caffeine,Pentoxifylline, and Kallikrein on hyperactivation of frozen bovine semen.Bio Med Research International. 2015; 1-7.

21. Malvezzi H, Sharma R, Agarwal A, Abuzenadah A, and Abu-Elmagd M. Sperm quality after density gradient centrifugation with three commercially available media: A controlled trial.Reproductive Biology and Endocrinology. 2014;12:121.

22. Henkel and Schill. Sperm preparation for ART.Reproductive Biology and Endocrinology. 2003;1:108.

23. Soderlund B, and Lundin $\mathrm{K}$. The use of silane-coated silica particles for density gradient centrifugation in invitrofertilization. Hum.Reprod. 2000;15 (4): 857-860.

24. Mehta J G. Intrauterine insemination with special reference to density gradient centrifugation. Intrauterine insemination. J. ReprodStem CellBiotechnol. 2012; 3(1): 9-21.

25. Oehninger S. Clinical and laboratory management of male infertility: An opinion onit's current status. Journal of Andrology. 2000:21(6):87-95.

26. Morrell JM. Upadte on semen technologies for animal breeding. Reprod. In Dom. Ani. 2006; 41:63-67.

27. Nabavi N, Todehdehghan F, and Shiravi A. Effect of Caffeine on motility and vitality of sperm and in vitro fertilization of outbreed mouse in T6 and M16 media.IranJReprod Med. 2013;11(9):741-6.

28. Colás C, Cebrián-Pérez JA, andMuiño-Blanco T.Caffeine induces ram sperm hyperactivation independent of cAMP-dependent protein kinase.IntJAndrol. 2010;33(1):e187-97.

29. Fakhrildin MB, Obaidi M., Hashim Z., and Selman MO. Assessment of IUI outcome for infertile couples with male infertility using sperm maxpure versus density gradient techniques. Int. J. Adv. Res.4(11):457-464.

30. Faque P,LehertP,LamotteM,Bettahar-Lebugle K, Bailly A, Diligent C,Cledat M, Pierrot P, Guenedal ML, and Sagot P. Clinical success of intrauterine insemination cycles is affected by the sperm preparation time.FertilSteril. 2014; 101: 1618-1623. 
31. Maha K, Khalid S, Rana A, and Nisreen K. Effect of incubation time on certain sperm function parameters following in vitro activation test.Iraqi Journal of Embryos and Infertility Researches (IJEIR). 2012; 2(3): 31-34.

32. Shams Alddin N.N, Al-Dujaily S.S, and Al-SultaniYK.In vitro sperm activation with Pentoxifylline and LCarnitine for infertile men semen using layering and sedimentation techniques.Iraqi Journal of Embryos and Infertility Researches (IJEIR). 2013; 3(6): 32-37. 